\title{
Beyond the body image: a qualitative study on how adults experience lower limb amputation
}

26(2) |80-19|

(c) The Author(s) 201 I

Reprints and permissions:

sagepub.co.uk/journalsPermissions.nav DOI: |0.1 |77/02692 |55||4|073|

cre.sagepub.com

(SAGE

\author{
Hugo Senra', Rui Aragão Oliveira', Isabel Leal' and \\ Cristina Vieira ${ }^{2}$
}

\begin{abstract}
Objective: To explore adults' experiences of lower limb amputation, focusing on the changes in self-identity related to the impairment.

Design: A cross-sectional and qualitative study, using semi-structured interviews. Interviews were transcribed, coded and analysed by two independent researchers.

Setting: A rehabilitation medicine service from a general public hospital.

Participants: A convenience sample of 42 patients with lower limb amputation performed after the age of 18 and followed up in the physical medicine and rehabilitation department of a general hospital.

Main outcome measures: A semi-structured interview, addressing three core areas: the emotional impact of amputation; the adjustment process; and the relation with the external resources.

Results: Eight themes emerged from interviews: reactions and feelings about becoming amputee; changes in own life; problems in well-being; relation with the prosthesis; self-perceptions; aims related to the rehabilitation and future plans; relation with the rehabilitation; and perceived social support. These results supported a theoretical model for the self-identity changes related to limb loss.

Conclusions: The self-identity changes after a lower limb amputation appear beyond the patient's body image and functioning, affecting the patient's awareness of the impairment, biographical self and any future projections.
\end{abstract}

\section{Keywords}

Amputation, lower limb, qualitative, self-identity

Received: 24 January 20II; accepted: 25 April 201 I

\section{Introduction}

A lower limb amputation is a surgical procedure that results from a serious medical condition such as diabetes, trauma or neoplasms. ${ }^{1}$ It has been described as an event usually associated with several changes in one's personal life,
'High Institute of Applied Psychology (ISPA), Psychology and Health Research Unit, Lisbon, Portugal

${ }^{2}$ Faculty of Human Kinetic, Technical University of Lisbon (UTL), Lisbon, Portugal

\section{Corresponding author:}

Hugo Senra, High Institute of Applied Psychology (ISPA) Psychology and Health Research Unit, Rua Jardim do Tabaco, 34, I I49-04I Lisboa, Portugal

Email: hugo_senra@hotmail.com 
affecting the individual's well-being, quality of life, and autonomy. ${ }^{2-6}$ Anxiety, depression, body-image anxiety and social discomfort have been pointed out as frequent consequences of a lower limb amputation. ${ }^{7-11}$ Both these consequences and the adjustment process to limb loss will depend on how the individual experiences the amputation ${ }^{3,7,12}$ and how his or her social support and rehabilitation are perceived. ${ }^{13-15}$

Several studies have been carried out to better understand the experience of lower limb loss in adults. The main personal areas focused on by these studies included: body image, ${ }^{16-18}$ relation with the artificial $\operatorname{limb},{ }^{5,7,19}$ phantom limb sensations and pain, ${ }^{20-22}$ coping strategies ${ }^{12,23,24}$ and perceived well-being. ${ }^{3}$ Regarding the qualitative studies developed in this field, several themes associated with this experience have been found: ${ }^{5,10,12,25-27}$ meanings of being an amputee; identity changes; meanings of using a prosthesis; coping with the loss; relation with own body; relations with the prosthesis and embodiment of an artificial limb; phantom and stump pain; feelings of vulnerability; resilience characteristics; social support changes; and need for emotional support.

In the majority of the studies on the adjustment to limb loss, two main changing processes of the patients' identity have been addressed: transformations in the individual's body image; and the embodiment process of the prosthesis. Although they are two important milestones of the adjustment process, the limb loss may also include other self-identity implications beyond the body image and the prosthesis embodiment. $^{28,29}$

In 2004, a comprehensive literature review by Horgan and MacLachlan ${ }^{29}$ stressed the implications of limb loss in self-identity as a practically non-explored subject. As far as we know, since this review until now, ten studies have been carried out on the experience of limb amputation. $3,5,12,19,23,25,26,30-32$ Only two of these 25,31 addressed the self-identity changes related to limb loss. Saradjian and colleagues' study ${ }^{25}$ stressed the importance of the individual's awareness of physical difference and the ability to integrate the prosthesis for the recovery process. Hamill and colleagues, ${ }^{31}$ in a qualitative study with eight lower limb amputees, found an interesting theme associated with self-identity changes: the renegotiation process of the new identity. According to the study, this process represents the subjects' transition to a new identity that causes an initial resistance and which is mediated by decisional, informational and social factors.

In this sense, it is a fact that the self-identity changes are beyond the body image changes and embodiment of the prosthesis. It is, therefore, a complex phenomenon that needs more attention and further investigation.

The current research aims at filling in the knowledge gap regarding the self-identity changes related to the lower limb amputation. The main goal of our study is to explore how adults experience lower limb amputation, with a special focus on the individuals' self-identity changes caused by limb loss.

\section{Method}

To perform this research, an exploratory crosssectional design, using qualitative methods, was adopted.

A convenience sample composed of 42 adult patients, followed up at the rehabilitation medicine service of a general public hospital, was used in this study. The inclusion criteria for patients were: being at least 20 years old; lower limb amputation performed after the age of 18 ; and being followed up in the rehabilitation medicine unit. Patients who did not meet inclusion criteria and/or had neurological and cognitive impairment were excluded, as it could interfere with the outcome. Patients at two different stages of rehabilitation were selected: those who were currently going through rehabilitation and those who had already finished it but continued to be followed up by the service to monitor their health and evaluate functional progression. In this hospital's service, the rehabilitation programmes are focused on enhancing 
patients' functional skills and on restoring independence through physical and occupational therapy. In general, no psychological or psychotherapeutic treatment is adopted during the follow-up, because it is not part of the formal clinical protocol.

Ethical procedures were adopted following the institutional protocol, and using an informed consent form.

\section{Data collection}

Demographical and clinical data were collected using a general questionnaire with simple closed questions.

Two face-to-face interviews lasting between 45 and 60 minutes were performed with each patient. The final 10-15 minutes of each interview were used to apply the general questionnaire, to assess demographic and clinical data. This protocol was designed to provide the patients with a trust setting in order to facilitate their narratives about their subjective experiences of becoming an amputee. The process of selecting patients was performed in partnership with the physician who coordinates the medical follow-up for amputees. A total of 65 patients were invited and 42 accepted and fulfilled all inclusion criteria.

Semi-structured interviews were conducted using open-ended questions that were created in order to be bias free and to allow any kind of narrative about each theme, as well as to facilitate the fluency of the participants' narratives about their experiences (see Appendix 1). These questions were elaborated to address three core areas: the emotional impact of becoming an amputee; the adjustment to amputation; and relation with external resources - social support and rehabilitation. Nonetheless, the interview was conducted without any predetermined sequence and respecting the patient's generated themes and questions. All interviews were conducted and audio-recorded by the same researcher (HS) who had no previous relationship with the participants. Although this researcher is experienced in clinical interviews, he was supervised during the whole study by another researcher (RAO).

The interviews continued being conducted even after researchers felt saturation had been reached in order to get the maximum variation of sample's characteristics. A total of 85 interviews were conducted for all 42 participants $(n=42)$. As can be seen in Table 1 , the mean age of participants was $61(\mathrm{SD}=13.5)$ and 35 were men. Most of them $(61.9 \%)$ suffered a transtibial amputation performed after the age of $40(59.5 \%)$. The main aetiology of the amputations was vascular disease $(83 \%)$. In terms of the state of rehabilitation, the same portion of patients $(50 \%)$ was in an ongoing rehabilitation process, and the remaining had already concluded it.

\section{Data analysis}

After the interviews were recorded, they were transcribed verbatim. Then, they were analysed using the Thematic and Categorical Analysis proposed by Bardin. ${ }^{33}$ In this method we adopted an inductive analysis modality, using an open coding technique, ${ }^{34,35}$ because we did not have any previous ideas or conceptualizations about the subjects. The content analysis was conducted and the following steps used: transcriptions were read at least twice, line by line to infer their global and specific meanings and structure; each narrative's specific meanings that generated open codes (semantic criteria) were identified and labelled; codes sharing common themes were gathered; themes were reanalysed and reviewed in order to be labelled and regrouped in thematic categories; thematic categories were validated by returning to the data through the patients' direct quotations. This procedure was performed by two researchers (HS, RAO), who had an exhaustive discussion and reflexion on each meaning, and defined criteria for each theme's categorization, during all the steps of the analysis. There was a high consensus between researchers, and disagreements were solved by returning to the transcripts. 
Table I. Characterization of the sample

\begin{tabular}{|c|c|c|}
\hline Variables & $N$ & Valid \% \\
\hline \multicolumn{3}{|l|}{ Age $(M=6 \mathrm{I} / \mathrm{SD}=13.5 / \operatorname{Min}=22 ; \operatorname{Max}=82)$} \\
\hline $22-45$ years & 4 & $9.5 \%$ \\
\hline $46-64$ years & 18 & $42.9 \%$ \\
\hline$\geq 65$ years & 20 & $47.6 \%$ \\
\hline \multicolumn{3}{|l|}{ Gender } \\
\hline Male & 35 & $83.3 \%$ \\
\hline Female & 7 & $16.7 \%$ \\
\hline \multicolumn{3}{|l|}{ Marital status } \\
\hline Married & 23 & $54.7 \%$ \\
\hline Single & 4 & $9.5 \%$ \\
\hline Divorced & 8 & $19 \%$ \\
\hline Widower & 7 & $16.8 \%$ \\
\hline \multicolumn{3}{|l|}{ Education level } \\
\hline Up to 9 years & 31 & $73.8 \%$ \\
\hline$>9$ years & $\mathrm{II}$ & $26.2 \%$ \\
\hline \multicolumn{3}{|c|}{ Age at amputation $(M=57.4 / \mathrm{SD}=14.2 / \mathrm{Min}=18 ; \mathrm{Max}=8 \mathrm{I})$} \\
\hline $18-39$ & 4 & $9.5 \%$ \\
\hline $40-64$ & 25 & $59.5 \%$ \\
\hline$\geq 65$ & 13 & $31 \%$ \\
\hline \multicolumn{3}{|l|}{ Type of lower limb amputation } \\
\hline Above knee (transfemoral 100\%) & 16 & $38.1 \%$ \\
\hline Below knee (transtibial 84.6\%; foot I5.4\%) & 26 & $61.9 \%$ \\
\hline \multicolumn{3}{|l|}{ Main aetiologies of lower limb amputation } \\
\hline Vascular disease & 35 & $83 \%$ \\
\hline Oncologic disease & 4 & $9.5 \%$ \\
\hline Trauma & 3 & $7.1 \%$ \\
\hline \multicolumn{3}{|c|}{ Time between amputation and interviews (years) $(M=2.3 / \mathrm{SD}=3.3 / \mathrm{Min}=0.3 ; \operatorname{Max}=17)$} \\
\hline Up to I year & 25 & $59.5 \%$ \\
\hline$>\mathrm{I}-5$ years & 14 & $33.3 \%$ \\
\hline$>5$ years & 3 & $7.1 \%$ \\
\hline \multicolumn{3}{|l|}{ State of rehabilitation } \\
\hline In progress & 21 & $50 \%$ \\
\hline Concluded & 21 & $50 \%$ \\
\hline \multicolumn{3}{|l|}{ Prosthesis wear } \\
\hline Not wearing yet & 24 & $57.1 \%$ \\
\hline Wearing & 18 & $42.9 \%$ \\
\hline
\end{tabular}




\section{Results}

Eight themes emerged from the three core categories of the interviews. The 'Emotional impact of amputation' category generated two themes: Reactions and feelings about becoming an amputee; and Changes in own life. The category 'Adjustment to amputation' generated the following four themes: Self-perceptions in terms of relation with the impairment; Relation with the prosthesis; Aims related to the rehabilitation and future plans; and Problems in well-being. The category 'Relation with the external resources' generated two themes: Perceived rehabilitation and Perceived social support.

\section{Reactions and feelings about becoming an amputee}

Patients' verbalizations about the diagnosis and becoming an amputee reported different kinds of meanings. Most $(\mathrm{n}=20)$ verbalized reactions and feelings such as sadness, shock, insurgence, surprise, non-acceptation of the situation, anger and suicidal thoughts.

At the beginning I was very revolted with the guy that caused the accident! I felt very angry... I stopped making love to my wife... I became more isolated from my colleagues and friends, and more dependent on my family... I was feeling very sad depressed... it was a shock to me! Until I started using the prosthesis, I was more dependent on others... However I still need a lot of help. (P39)

Some patients $(n=5)$ also verbalized pain relief as a consequence of the amputation. In these cases the limb loss seems to have a less negative resonance and to be associated with pain cessation.

It was a relief, because the pain was very strong and unbearable!! I couldn't sleep! I couldn't live with that pain, and now I feel better! (P2)
There were also patients who avoided the theme $(n=3)$, or rationalized it $(n=5)$ and did not verbalize any feelings related to the diagnosis or the amputation.

I always reacted well, and placed all my trust in doctors! It had to be done, because my leg was very ill and I could die!! I didn't feel traumatized nor had any complex with it! I faced it well and said 'let's go on with it'! (P10)

\section{Changes in own life}

Regarding this theme, most patients $(n=38)$ reported feelings and ideas about a life before and after the limb loss. Patients reported changes caused by the amputation both in their inner and relational life, such as difficulties with basic skills and daily activities - loss of independence; inferiority feelings; problems regarding well-being; negative changes in their professional life and achievements; identity changes; changes in their affective or sexual life; and feeling abandoned by others.

After the amputation I stopped working and doing many things I love... I had to cope with this! I was a very dynamic person; I worked a lot and had a good income! Today I can't do many things, I became more dependent on others, with less autonomy and I changed myself! Today I'm a more nervous and explosive person... I liked reading and today I don't... many things changed for me. (P39)

\section{Self-perceptions in terms of the relation with the amputation}

Fifteen $(n=15)$ patients recognized and identified themselves as impaired. These patients accepted and used assistive devices, including prostheses; adapted their lives to the new condition; talked about themselves as amputees; and did not tend to be isolated from others. 
Today I'm a new person! I returned to school and to work! I bodyboard! My life is not the same but it (amputation and prosthesis) is already a part of me! I adjusted my life to it, but I haven't stopped doing my favourite hobbies or meeting my friends. It was worse at the beginning, when I became an amputee, but now it's different! (P24)

The majority of patients $(n=27)$ continue to resist assistive devices and/or do not accept their new situation at all. They have already begun to cope with their loss and using some assistive devices, but the impairment is not a part of them, yet. These patients are in the transition from perceiving themselves as 'not amputee' to 'amputee'.

Rehabilitation has helped me, but it's very hard for me, and I don't know if I'll be able to walk alone! The prosthesis is painful... I can't accept this situation because it's revolting being like this...without driving, walking, working...it's very sad depending on others...I was a very dynamic man before this happened. (P9)

\section{Relation with the prosthesis}

Both for patients who were wearing the prosthesis and for those who were still learning how to use it, the prosthesis was a stressed theme. While some patients $(n=14)$ expressed negative attributions, such as a source of pain, others $(n=28)$ associated it with improvements in autonomy, in daily life activities, in basic skills, or as being a part of themselves $(n=2)$.

It is precious to me! Without it I was another person. I couldn't walk alone, bath alone, drive, or meet my friends! It is a part of me. (P2)

\section{Aims related to the rehabilitation and future plans}

Most of patients $(n=38)$ verbalized personal aims related to the rehabilitation and general recovery, such as to improve basic skills and daily life activities; to be able to wear the prosthesis. The majority of patients just verbalize future plans for recovery in terms of becoming more independent and improving some daily living skills. Only two patients referred to returning to work, even another work and lifestyle, as a main future goal after the rehabilitation was finished.

Rehabilitation is important because it is helping me to return to do my daily life and most importantly to walk again! I have hope in the prosthesis! It will help me become a different person and leave the wheelchair. (P14)

\section{Problems in well-being}

The majority of patients $(n=29)$ report physical or emotional complaints often associated with their medical condition: pain; sadness; depressive humour; sleep disorders; anxiety; and irritability. Regarding pain, most of them $(n=28)$ did not report stump pain or phantom limb pain $(n=29)$. Those who reported stump pain associated it with a decrease in their quality of life and with poor adjustment to the new situation.

Lately I have been having trouble sleeping! In fact, I'm a little depressed, my wife knows...I get easily annoyed! I've been feeling this since the amputation! (P7)

\section{Perceived rehabilitation}

Most patients $(n=39)$ reported positive feelings and their satisfaction regarding the rehabilitation programme and staff. They stressed the new skills learned, the programme, the environment, and the possibility of using the prosthesis. The remaining three patients saw the rehabilitation as an inadequate or an insufficient resource. 
Rehabilitation has been very helpful for me...I am able to walk alone again! The staff has been lovely and I'm feeling like another person! ( P27) It's very hard for me! Probably for other patients it's easier, but for me... Exercises won't give me my leg back! It's very sad being like this! (P9)

\section{Perceived social support}

Some patients $(n=27)$ verbalized their satisfaction with the support they received from their family and friends, considering it a valuable resource to improve their adjustment. The others $(n=15)$ reported poor or inadequate social support.

My family is the main reason for my recovery! They have been giving me a lot of support, helped me to walk again and to cope with this situation. (P4)

I am alone! Nobody cared about me... My sons left me alone... they have their lives... I miss my wife! She died last year. (P38)

\section{Rehabilitation and the experience of limb loss}

The frequencies of each theme that emerged associated with the experience of limb loss, for patients going through rehabilitation and for those who have already completed it, are presented in Table 2.

\section{Discussion}

The main purpose of the current study was to explore adults' experience of lower limb amputation and its implications for their self-identity. Because our patient interviews were not marked out by any structured questionnaire or quantitative instrument, the experience of amputation was explored in depth and through true life stories. The qualitative data showed several aspects of this experience, including different selfidentity changes arising from the situation of becoming an amputee.
Our qualitative data supports a dynamic model of the self-identity changes experienced by the patients, composed of three core phases (Figure 1): the individual's first contact with the amputation and his or her self-awareness of the impairment; change in the individual's selfidentity in several domains of the self; and the final embodiment of a new self-identity in consequence of becoming an amputee. Unlike previous studies, the identity changes were not only addressed in terms of body image ${ }^{10,16-18}$ and prosthesis embodiment, ${ }^{7,9,26}$ but also in other dimensions of the self.

With regard to the first phase of the selfidentity changes, our study retrieved two major kinds of verbalizations that surround the emotional impact of amputation: patients who presented an emotional response to the situation of becoming amputee, addressing their feelings and reactions and who, therefore, appeared to be more aware of their impairment; and patients who did not exhibit any emotional resonance to amputation and its implications and who, therefore, appeared to be less aware of their situation. Thus, the self-awareness of the impairment arises as the first trigger to self-identity changes after the amputation. Without selfawareness, patients could not experience losses in several life domains and, consequently, feelings and reactions such as sadness, revolt, shock or catastrophizing. These feelings and reactions were also retrieved by other qualitative stu$\operatorname{dies}^{3,5,10,25}$ but self-awareness was not a theme addressed by these studies, except in the Saradjian's qualitative study. ${ }^{25}$ Nevertheless, there are two main differences between this study and ours: first, the self-awareness it addressed was more focused on changes in body image and its restoration after the donning of the prosthesis, while ours looked at the selfidentity changes beyond body image, including other dimensions of the individual's self; second, its sample was made up of upper limb amputees, while ours is lower limb amputees.

The second phase of the self-identity changes after the amputation concerns a set of domains of the self relating to personal and relational 
Table 2. Frequency of emerged themes in two stages of rehabilitation

\begin{tabular}{|c|c|c|c|}
\hline \multirow[b]{2}{*}{ Experience of lower limb loss } & & \multicolumn{2}{|c|}{ Rehabilitation } \\
\hline & & $\begin{array}{l}\text { In progress } \\
(n=2 I)\end{array}$ & $\begin{array}{l}\text { Finished } \\
(n=2 I)\end{array}$ \\
\hline \multirow[t]{2}{*}{ Verbalized reactions and feelings } & Verbalized & $14(67 \%)$ & 15 (7|\%) \\
\hline & Not verbalized & $7(33 \%)$ & $6(29 \%)$ \\
\hline \multirow[t]{2}{*}{ Verbalized changes in own life } & Verbalized & $20(95 \%)$ & $20(95 \%)$ \\
\hline & Not verbalized & I (5\%) & I (5\%) \\
\hline \multirow[t]{2}{*}{ Relation with Prosthesis } & Positive attributions & $13(62 \%)$ & $17(81 \%)$ \\
\hline & Negative attributions & $5(24 \%)$ & $4(19 \%)$ \\
\hline \multirow[t]{2}{*}{ Relation with the impairment and self-perceptions } & As in transition & $18(86 \%)$ & $9(43 \%)$ \\
\hline & As amputated & $3(14 \%)$ & $12(57 \%)$ \\
\hline \multirow[t]{2}{*}{ Perceived problems in well-being } & Reported & $17(81 \%)$ & $12(57 \%)$ \\
\hline & Not reported & $4(19 \%)$ & $9(43 \%)$ \\
\hline \multirow[t]{2}{*}{ Stump pain } & Reported & $5(24 \%)$ & $9(43 \%)$ \\
\hline & Not reported & $16(76 \%)$ & $12(57 \%)$ \\
\hline \multirow[t]{2}{*}{ Phantom limb pain } & Reported & $6(29 \%)$ & 7 (33\%) \\
\hline & Not reported & 15 (7I\%) & $14(67 \%)$ \\
\hline \multirow[t]{2}{*}{ Perceived social support } & As a good resource & $12(57 \%)$ & 17 (8I\%) \\
\hline & As inadequate & $9(43 \%)$ & $4(19 \%)$ \\
\hline
\end{tabular}

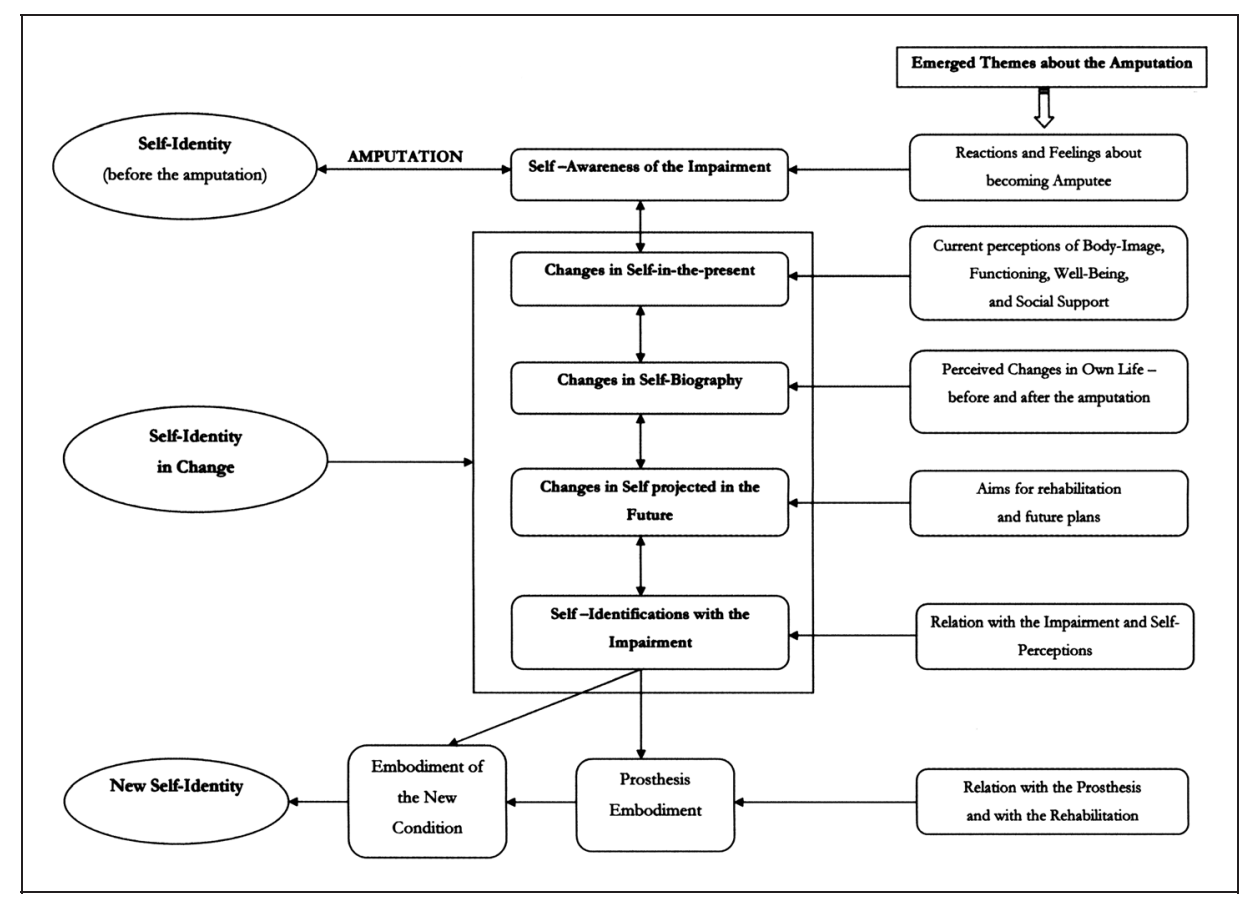

Figure I. Model for self-identity changes related to lower limb amputation. 
losses and transformations. In the present, the patient becomes aware of his or her new physical appearance, functional limitations and quality of well-being and social support. This is the domain which most of the previous studies have approached. ${ }^{3,13,16}$ In agreement with these studies, our results also point to body image anxiety and the patient looking for the prosthesis as two common reactions at the start of the adjustment process.

Beyond body image, patients also addressed other important areas of the individual's self. The results showed that, in terms of selfbiography, most patients addressed their amputation as a potential break with the past and with what they were waiting for in the future. This break was not only with regard to body image, but also in patients' very identity, personality, functioning, sex life and relationships.

In terms of future projection of the self, most patients only referred to their desire to return to the same skills and activities as previously (to walk alone or to drive). This fact appears to be explained by two main reasons: most patients are able to return to the same activities without great alterations; most of them are elderly of non-working age and, therefore, they do not need to ponder a work change, with its inherent adaptations and restrictions.

Concerning self-identification with the impairment, this has to do with two embodiment processes: the prosthesis and the new condition of being amputated. These embodiment processes are inwardly dependent on the changes in the patient's self (biography; present; and future projections), and the internal and external resources he or she has to deal with the impairment. In the same way, several studies $9,25,30,36$ have stressed the prosthesis wearing as an important milestone for the patients' self-worth and body image restoration, autonomy recovery and well-being improvement.

In terms of embodiment of a new selfidentity, our results showed that most patients are in transition between being identified with the impairment and, therefore, renegotiating their new identity. This is a well-supported finding by Hamil's study, ${ }^{31}$ where the process of transition to a new identity was also found in a group of amputees. The final phase of this process, to reach a new self-identity, is completely dependent on how the patient performed his or her self-identity changes in the other domains. Therefore, there is no specific sequence or predetermined course for the self-identity changes. They are interrelated and dynamic, because they operated in several parts of the same self.

Despite the fact that our model has a high correspondence with our patients' narratives of limb loss, we also found other patients who reported a different experience. These patients appraised the amputation positively, and reported fewer losses and changes in their selfidentity domains. Even though they did not represent the larger portion of patients who had an amputation, they arise as a different group of patients who tend to report less pain, more social functioning and fewer health concerns, as the literature has stressed. ${ }^{32}$

Our results suggested that rehabilitation may have a positive effect on a patient's relation with their prosthesis and therefore may increase their well-being, satisfaction and functioning. Nonetheless, a number of patients continue to report problems in well-being, even after rehabilitation has finished. This finding appears to be explained by the absence of systematized psychological or psychotherapeutic work provided to our patients during the rehabilitation period. This psychotherapeutic work has been proven to be an indispensable support throughout the adjustment process to limb loss. ${ }^{37,38}$

Some limitations of this study need to be acknowledged. First, even though our sample's size is large enough for a qualitative study, it is a relatively selected sample mainly composed of subjects who were amputated as a consequence of vascular disease. Therefore further research including more patients with other types of aetiology, such as trauma or cancer, is needed.

Second, the interviews were only semistructured. Even though the interviews were conducted with the concern of being bias free, 
three core areas were predefined to be addressed. Interviews tended to be steered towards these areas and, therefore, they could have biased the results.

Third, because our study is a cross-sectional study, rather than a longitudinal study, the evolution of the patients' adjustment to limb loss overtime was not assessed. It would be interesting to perform this assessment in future studies.

Finally, although our findings bring into light a new model for the changes in patient identity related to becoming an amputee, it cannot be generalized to other samples, and only reveals the experiences of our patients. Thus, it only provides relevant clues to be taken into account in clinical practice and future research.

Our study raises some important new findings on an understudied aspect of the experience of limb loss: the self-identity changes. Even though some of the referred patients' themes have been addressed by previous studies, they have never been explored and approached as being integrated, and as being part of the whole self. The resulting theoretical model offers a great picture of these self-identity changes, points to some clues concerning the adjustment process and identifies which areas of the patients' functioning might be more affected by the impairment. These findings are particularly important for understanding a patient's course of adjustment and planning some psychotherapeutic targets during clinical follow-up.

\section{Clinical messages}

- The self-identity changes were reported beyond the body image, affecting the patients' awareness of the impairment, biographical self and its future projections.

- An assessment and intervention work directed to these dimensions of the patient's self might be a good practice, especially for psychologists, during the rehabilitation and follow-up periods.

\section{Funding}

This work was supported by the Foundation for Science and Technology of the Portuguese Ministry of Science and Technology (www.fct.mctes.pt) through a four-year grant award (Ref. SFRH/BD/ 29987/2006).

\section{References}

1. Moxey P, Hofman R, Hinchliffe R, Jones K, Thompson $\mathrm{M}$ and Holt P. Epidemiological study of lower limb amputation in England between 2003 and 2008. Br J Surg 2010; 97: 1348-1353.

2. Buzgová R, Buzga M and Kristiníková J. WHOQOL: Assessment of quality of life in patients after lower limb amputation. Acta Med Martiniana 2009; 9: 33-40.

3. Bosmans J, Suurmeijer T, Hulsink M, van der Schans C, Geertzen J and Dijkstra P. Amputation, phantom pain and subjective well-being: a qualitative study. Int $J$ Rehabil Res 2007; 30: 1-8.

4. Demet K, Martinet N, Guillemin F, Paysant J and André J. Health related quality of life and related factors in 539 persons with amputation of upper and lower limb. Disabil Rehabil 2003; 25: 480-486.

5. Murray C. Being like everybody else: the personal meanings of being a prosthesis user. Disabil Rehabil 2009; 31: $573-581$.

6. de Godoy J, Braile D, Buzatto S, Longo O and Fontes O. Quality of life after amputation. Psychol Health Med 2002; 7: 397-400.

7. Gallagher P and MacLachlan M. Adjustment to an artificial limb: a qualitative perspective. J Health Psychol 2001; 6: 85-100.

8. Coffey L, Gallagher P, Desmond D, Horgan O and MacLachlan M. Psychosocial adjustment to diabetes related amputation. Diabet Med 2009; 26: 1063-1067.

9. Atherton R and Robertson N. Psychological adjustment to lower limb amputation amongst prosthesis users. Disabil Rehabil 2006; 28: 1201-1209.

10. Rybarczyk B, Edwards R and Behel J. Diversity in adjustment to a leg amputation: Case illustrations of common themes. Disabil Rehabil 2004; 26: 944-953.

11. Singh R, Ripley D, Pentland B, et al. Depression and anxiety symptoms after lower limb amputation: the rise and fall. Clin Rehabil 2009; 23: 281-286.

12. Sjödahl C, Gard G and Jarnlo G. Coping after transfemoral amputation due to trauma or tumour - a phenomenological approach. Disabil Rehabil 2004; 26: 851-861.

13. Williams R, Ehde D, Smiths D, Czerniecki J, Hoffman A and Robinson L. A two-year longitudinal study of social support following amputation. Disabil Rehabil 2004; 26: 862-874.

14. Williamson GM, Schulz R, Bridges MW and Behan AM. Social and psychological factors in adjustment to limb amputation. J Soc Behav Pers 1994; 9: 249-268. 
15. Hanley M, Jensen M, Ehde D, Hoffman A, Patterson D and Robinson L. Psychosocial predictors of long-term adjustment to lower-limb amputation and phantom limb pain. Disabil Rehabil 2004; 26: 882-893.

16. Murray $\mathrm{C}$ and Fox J. Body image and prosthesis satisfaction in the lower limb amputee. Disabil Rehabil 2002; 24: 925-931.

17. Braekey J. Body image: the lower limb amputee. J Prosthet Orthot 1997; 9: 58-66.

18. Mayer A, Kudar K, Bretz K and Tihanyi J. Body schema body awareness. Prosthet Orthot Int 2008; 32 : 363-382.

19. Stokes D, Curzio J, Berry A, Bacon E, Morten M and Barker L. Pre prosthetic mobility: The amputees' perspectives. Disabil Rehabil 2009; 31: 138-143.

20. Borje S, Bosmans J, van der Schans C, Geertzen J and Dijkstra P. Phantom pain: a sensitivity analysis. Disabil Rehabil 2004; 26: 905-910.

21. Ephraim P, Wegener S, MacKenzie E, Dillingham T and Pezzin L. Phantom pain, residual limb pain, and back pain in amputees: results of a national survey. Arch Phys Med Rehabil 2005; 9: 58-66.

22. Gallagher P, Allen D and MacLachlan M. Phantom limb pain and residual limb pain following lower limb amputation: a descriptive analysis. Disabil Rehabil 2001; 23: $522-530$.

23. Oaksford K, Frude N and Cuddihy R. Positive coping and stress-related psychological growth following lower limb amputation. Rehabil Psychol 2005; 50: 266-277.

24. Desmond D and MacLachlan M. Coping strategies as predictors of psychosocial adaptation in a sample of elderly veterans with acquired lower limb amputations. Soc Sci Med 2006; 62: 208-216.

25. Saradjian A, Thompson A and Datta D. The experience of men using an upper limb prosthesis following amputation: positive coping and minimizing feeling different. Disabil Rehabil 2008; 30: 871-883.

26. Murray C. An interpretative phenomenological analysis of the embodiment of artificial limbs. Disabil Rehabil 2004; 26: 963-973.

27. Unwin J, Kacperek L and Clarke C. A prospective study of positive adjustment to lower limb amputation. Clin Rehabil 2009; 23: 1044-1050.

28. Parkes C. Psycho-social transitions: Comparison between reactions to loss of a limb and loss of a spouse. Br J Psychiatry 1975; 127: 204-210.

29. Horgan $\mathrm{O}$ and MacLachlan M. Psychosocial adjustment to lower-limb amputation: a review. Disabil Rehabil 2004; 26: 837-850.

30. Van der Linde H, Hofstad C, Geertzen J, Postema K and Van Limbeek J. From satisfaction to expectation: the patient's perspective in lower limb prosthetic care. Disabil Rehabil 2007; 29: 1049-1055.

31. Hamill R, Carson S and Dorahy M. Experiences of psychosocial adjustment within 18 months of amputation: an interpretative phenomenological analysis. Disabil Rehabil 2010; 32: 729-740.

32. Couture M, Desrosiers J and Caron C. Cognitive appraisal and perceived benefits of dysvascular lower limb amputation: a longitudinal study. Arch Gerontol Geriatr 2011; 52: 5-11.

33. Bardin L. [Content analysis], fourth edition. Lisboa: Edições 70, 2008.

34. Creswell JW. Research design: qualitative, quantitative and mixed methods approach, second edition. London: SAGE, 2008.

35. Eto $\mathrm{S}$ and Kyngäs $\mathrm{H}$. The qualitative content analysis process. J Adv Nurs 2008; 62: 107-115.

36. Esquenazi A. Amputation rehabilitation and prosthetic restoration. From surgery to community reintegration. Disabil Rehabil 2004; 26: 831-836.

37. Oliveira RA and Fragoso MJ. Identity, rehabilitation process and the adjustment to disability. Mediterranean J Phys Rehabil Med 2006; 42: 52-55.

38. Rusin M and Uomoto J. Psychotherapeutic interventions. In: Frank RG, Rosenthan M, Caplan B (eds) Handbook of rehabilitation psychology, second edition. Washington DC: American Psychological Association, 2010, pp.259-271.

\section{Appendix I - Core questions for patient interviews (resume)}

1. Beginning of the interview:

a. I would like to know more about you, your history, what has happened to you, your feelings, how did you come here?

2. Psychological impact

a. What has happened to you? How did you know that you were having problems with your leg?

b. Do you remember the day you were talking with your doctor about it? How did you feel? How did you deal with it?

c. Do you consider there is a life before the amputation and after the amputation? Is there one person before, and another after the amputation? What else has changed?

3. Adjustment to limb loss

a. What do you think about the prosthesis? How was your adaptation to the prosthesis? Has it being useful? 
b. What personal goals do you have regarding the rehabilitation? Do you have any plans for the future?

c. How did/is your rehabilitation go/going? Was it/has it been helpful?

d. How do you feel now? Are you having any particular problems?
4. Relation with the external resources

a. How did your family and friends react to your situation?

b. Have you had significant support from your family, friends, or others? 
Copyright of Clinical Rehabilitation is the property of Sage Publications, Ltd. and its content may not be copied or emailed to multiple sites or posted to a listserv without the copyright holder's express written permission. However, users may print, download, or email articles for individual use. 